\title{
Impact of sex, age, and ethnicity/race on the survival of patients with rectal cancer in the United States from 1988 to 2012
}

\author{
Martin D. Berger ${ }^{1}$, Dongyun Yang${ }^{2}$, Yu Sunakawa ${ }^{1}$, Wu Zhang ${ }^{1}$, Yan Ning ${ }^{1}$, \\ Satoshi Matsusaka ${ }^{1}$, Satoshi Okazaki ${ }^{1}$, Yuji Miyamoto ${ }^{1}$, Mitsukuni Suenaga ${ }^{1}$, \\ Marta Schirripa ${ }^{1}$, Annika Medea Lenz ${ }^{1}$, Pierre Bohanes ${ }^{1}$, Afsaneh Barzi ${ }^{1}$, Jane C. \\ Figueiredo $^{1,2}$, Diana L. Hanna ${ }^{1}$, Heinz-Josef Lenz ${ }^{1,2}$ \\ ${ }^{1}$ Division of Medical Oncology, Norris Comprehensive Cancer Center, Keck School of Medicine, University of Southern \\ California, Los Angeles, CA, USA \\ ${ }^{2}$ Department of Preventive Medicine, Norris Comprehensive Cancer Center, Keck School of Medicine, University of Southern \\ California, Los Angeles, CA, USA
}

Correspondence to: Heinz-Josef Lenz, email: lenz@usc.edu

Keywords: age, ethnicity/race, sex, rectal cancer, survival

Received: May 14, $2016 \quad$ Accepted: July 01, $2016 \quad$ Published: July 19, 2016

\section{ABSTRACT}

Most studies report on colon and rectal cancers collectively, even though biologic and prognostic differences exist between these disease entities. Here, we investigated the effects of sex, age, and ethnicity/race on rectal cancer (RC) mortality by stage focusing on differences before and after 2004.

Using the SEER database, we identified 105,511 patients diagnosed with RC from 1988-2012. Main outcomes were disease-specific survival (DSS) and overall survival (OS).

In patients with stage I-III RC, women achieved a longer DSS (HR 0.87, P < 0.001 ) than men, independent of age, from 1988-2012. In stage IV disease, the sex disparity favoring women was limited to the age 18-44 yr cohort (DSS HR 0.79, $P<$ $0.001)$. The sex difference in DSS $\left(P_{\text {interaction }}=0.009\right)$ was significantly reduced from 2004 to 2012 across all ages. Hispanics and Native Americans with locoregional RC had inferior DSS relative to Whites from 1988-2003, but these differences were not evident from 2004-2012 $\left(P_{\text {interaction }}=0.001\right)$. Additionally, Asians with stage I-III RC had superior DSS from 2004 on compared to Whites. Mortality in African American patients improved modestly overall and remained significantly higher than other ethnicities/races across all stages.

Sex disparities have narrowed in patients with metastatic RC, but persist in patients with stage I-III disease. These differences are most evident among young patients (18-44 years), where sex disparities have even widened in stage I-III disease. While outcomes have improved for Asians, Hispanics, and Native Americans with stage I-III rectal cancer, black-white disparities remain in all disease stages.

\section{INTRODUCTION}

Rectal cancer (RC) is a leading cause of morbidity and mortality from gastrointestinal malignancy [1]. While cancer-specific survival has improved in the United States [2], demographic disparities remain for reasons which are incompletely understood. For instance, there has been a steady rise in the incidence and mortality of RC among individuals younger than 50 years old [3-5]. Indeed, younger patients are more likely to present with rectal than proximal colon tumors, and with poorly differentiated and late-stage cancers [6].

With regards to ethnicity/race, existing evidence has shown consistently worse outcomes for African Americans compared to Whites, even after adjusting for socioeconomic and insurance status [7, 8]. However, these findings are restricted to patients with colorectal cancer (CRC), whereas outcome data specific for RC are lacking.

Over the last three decades, the management of RC has witnessed the introduction of several cytotoxic and 
biologic drugs, as well as the shifting of perioperative chemoradiotherapy from the adjuvant to the neoadjuvant setting for locally advanced disease [9]. In 2004, the use of oxaliplatin was expanded into the adjuvant and firstline metastatic settings, and the first targeted agents were approved for metastatic disease (i.e. bevacizumab, cetuximab) [10-13]. Whether these advancements have variably influenced outcomes in different populations has been largely un-explored.

Furthermore, although survival disparities in RC have been identified, many clinical and epidemiologic studies have examined colon and rectal cancers collectively or concentrated on a particular demographic or time period [6, 14-17]. A comprehensive investigation specific to RC and spanning recent changes in standard of care is lacking. Here, we sought to evaluate the impact and interactions of sex, age, and ethnicity/race on the survival of patients with RC. We then compared stagespecific survival trends by year of diagnosis, focusing on differences before and after 2004.

\section{RESULTS}

\section{Patient, tumor, and treatment characteristics}

Among 105,511 patients diagnosed with rectal cancer between 1988 and 2012 in this study, 58.5\% were male and $41.5 \%$ female (Table 1). The median age at diagnosis was 66 years, and $54.3 \%$ of patients were 65 years or older. The cohort included $74.5 \%$ Whites $(\mathrm{n}=$ 78,593), 8\% Asians ( $\mathrm{n}=8,403), 8 \%$ African Americans $(\mathrm{n}=8,473), 8.9 \%$ Hispanics $(\mathrm{n}=9,388)$, and $0.6 \%$ Native Americans $(\mathrm{n}=654)$. Hispanics and Native Americans were diagnosed at a younger age than Whites. Here, the greatest difference is seen between Native American (median 60 years) and white women (median 69 years) ( $P<0.001$ for all comparisons) (Supplementary Table 1). Among Whites, African Americans and Asians, women were diagnosed at an older age than men ( 69 vs 66 yrs, 64 vs 62 yrs, and 65 vs 64 yrs, respectively, $P<0.001$ for all comparisons) (Supplementary Table 1).

The stage distribution was as follows: $34.7 \%$ stage I $(n=36,598), 23.5 \%$ stage II $(n=24,803), 25.7 \%$ stage III $(\mathrm{n}=27,090)$, and $16.1 \%$ stage IV $(\mathrm{n}=17,020)$. Most patients $(80.6 \%)$ underwent local tumor resection or radical surgery. $53.7 \%$ received neoadjuvant and $43.3 \%$ adjuvant radiotherapy. The proportion of patients diagnosed in 1988 to 2003 and 2004 to 2012 were $48.5 \%$ $(\mathrm{n}=51,171)$ and $51.5 \%(\mathrm{n}=54,340)$, respectively.

\section{Sex, age, and survival by stage and year of diagnosis}

In a multivariable Cox proportional hazards regression model (Table 2), women with stage I-III RC had a significantly longer DSS (HR 0.87, 95\% CI 0.84,
$0.89)$ and OS (HR $0.78,95 \%$ CI $0.77,0.80)$ than men $(P<$ $0.001)$. In stage IV disease, women maintained a modest advantage for OS (HR 0.96, 95\% CI 0.93, 0.99, $P=0.019$ ) but not for DSS (HR 0.97, 95\% CI 0.94, 1.01, $P=0.16$ ).

With regards to age, patients younger than age 55 achieved the longest DSS (HR 0.66, 95\% CI 0.64, 0.69, $P$ $<0.001$ ) and OS (HR 0.47, 95\% CI 0.46, 0.49, $P<0.001$ ) compared to aged 55 or older among those with stage I-III disease. In patients with stage IV rectal cancer, those aged 45-54 had the longest DSS (HR 0.70, 95\% CI 0.66, 0.74, $P$ $<0.001$ ) and OS (HR 0.64, 95\% CI 0.60, 0.67, $P<0.001)$ compared to patients older than 75 years $(P<0.001)$.

We then examined the interaction between age and sex on survival (Table 3 ). Within the stage I-III cohort, women had a significantly longer DSS $\left(P_{\text {interaction }}=0.27\right)$ and $\operatorname{OS}\left(P_{\text {interaction }}=0.94\right)$, independent of age. In contrast, in patients with stage IV disease, the impact of sex on DSS $\left(P_{\text {interaction }}=0.013\right)$ and $\operatorname{OS}\left(P_{\text {interaction }}=0.005\right)$ was limited to the youngest age group (18-44 years).

When stratified by year of diagnosis, the influence of sex on DSS was consistent in patients with stage I-III rectal cancer overall $\left(P_{\text {interaction }}=0.46\right)$ (Table 4). However, there was a significant interaction between sex and year of diagnosis for OS, with a narrowing of sex differences over time $\left(P_{\text {interaction }}=0.04\right)$ (Table 4). Among patients aged 18-44 years, there was a trend towards a wider sex disparity from 2004 to 2012 (DSS HR 0.75, $P_{\text {interaction }}$ $\left.=0.090 ; \mathrm{OS} H R 0.73, P_{\text {interaction }}=0.11\right)$ as compared to 1988 to 2003 (DSS HR 0.92, OS HR 0.88) (Figure 1, Supplementary Table 2). This trend was not evident in the other age groups. In patients with metastatic disease, the sex difference in DSS $\left(P_{\text {interaction }}=0.009\right)$ was significantly reduced from 2004 to 2012 , with a similar trend for OS $\left(P_{\text {interaction }}=0.050\right)$ across all ages (Table 4$)$.

\section{Ethnicity/race and survival by stage and year of diagnosis}

Ethnicity/race was an independent prognostic factor across all stages of rectal cancer, with the most pronounced disparities seen among African American patients (Table 2). In stage I-III disease, African American patients had a significantly shorter DSS and OS compared to Whites (DSS HR 1.30, 95\% CI 1.24, 1.37; OS HR 1.23, 95\% CI 1.18, $1.27, P<0.001$ for both comparisons), Hispanic, and Asian patients. Similarly, in stage IV disease, African Americans had an inferior DSS relative to Whites (HR 1.14, 95\% CI $1.08,1.22, P<0.001)$, Hispanic, and Asian patients as well as a significantly shorter OS compared to all other ethnicities/ races. Furthermore, Hispanics with stage I-III disease had a significantly shorter DSS (HR 1.10, 95\% CI 1.05, 1.16, $P<0.001)$ compared to Whites. Asians had a modestly improved DSS and OS relative to Whites (DSS HR 0.93, 95\% CI 0.88, 0.99; OS HR 0.88, 95\% CI 0.84, 0.92, $P<$ 0.001 for both comparisons) and Hispanics, and the longest OS amongst all ethnicities/races with stage I-III disease. 
Table 1: Characteristics of patients with rectal cancer, SEER 1988-2012

\begin{tabular}{|c|c|c|c|}
\hline & All Patients & Stage I-III & Stage IV \\
\hline Characteristic & $N=105,511$ & $N=88,491$ & $N=17,020$ \\
\hline \multicolumn{4}{|l|}{ Sex } \\
\hline Male & $61693(58.5 \%)$ & $51252(57.9 \%)$ & $10441(61.3 \%)$ \\
\hline Female & $43818(41.5 \%)$ & $37239(42.1 \%)$ & $6579(38.7 \%)$ \\
\hline \multicolumn{4}{|l|}{ Age, years } \\
\hline Median (interquartile range) & $66(56-76)$ & $67(56-76)$ & $64(54-74)$ \\
\hline $18-44$ & $6903(6.5 \%)$ & $5438(6.1 \%)$ & $1465(8.6 \%)$ \\
\hline $45-54$ & $16786(15.9 \%)$ & $13697(15.5 \%)$ & $3089(18.1 \%)$ \\
\hline $55-64$ & $24570(23.3 \%)$ & $20329(23.0 \%)$ & $4241(24.9 \%)$ \\
\hline $65-74$ & $27720(26.3 \%)$ & $23542(26.6 \%)$ & $4178(24.6 \%)$ \\
\hline 75 and older & $29532(28.0 \%)$ & $25485(28.8 \%)$ & $4047(23.8 \%)$ \\
\hline \multicolumn{4}{|l|}{ Ethnicity/Race } \\
\hline White & $78593(74.5 \%)$ & $66574(75.2 \%)$ & $12019(70.6 \%)$ \\
\hline African American & $8473(8.0 \%)$ & $6725(7.6 \%)$ & $1748(10.3 \%)$ \\
\hline Asian & $8403(8.0 \%)$ & $7056(8.0 \%)$ & $1347(7.9 \%)$ \\
\hline Hispanic & $9388(8.9 \%)$ & $7629(8.6 \%)$ & $1759(10.3 \%)$ \\
\hline Native American & $654(0.6 \%)$ & $507(0.6 \%)$ & $147(0.9 \%)$ \\
\hline \multicolumn{4}{|l|}{ Histology } \\
\hline Non-mucinous adenocarcinoma & $94735(89.8 \%)$ & $79875(90.3 \%)$ & $14860(87.3 \%)$ \\
\hline Mucinous adenocarcinoma & $6512(6.2 \%)$ & $5443(6.1 \%)$ & $1069(6.3 \%)$ \\
\hline Other & $4264(4.0 \%)$ & $3173(3.6 \%)$ & $1091(6.4 \%)$ \\
\hline \multicolumn{4}{|l|}{ Differentiation } \\
\hline Good & $8456(8.0 \%)$ & $7642(8.6 \%)$ & $814(4.8 \%)$ \\
\hline Moderate & $67967(64.4 \%)$ & $58791(66.5 \%)$ & $9176(53.9 \%)$ \\
\hline Poor & $16509(15.7 \%)$ & $12687(14.3 \%)$ & $3822(22.5 \%)$ \\
\hline Not determined & $12579(11.9 \%)$ & $9371(10.6 \%)$ & $3208(18.8 \%)$ \\
\hline \multicolumn{4}{|l|}{ Lymph Nodes Examined } \\
\hline$<12$ nodes & $71544(67.8 \%)$ & $58369(66.0 \%)$ & $13175(77.4 \%)$ \\
\hline$\geq 12$ nodes & $31333(29.7 \%)$ & $28138(31.8 \%)$ & $3195(18.8 \%)$ \\
\hline Unknown & $2634(2.5 \%)$ & $1984(2.2 \%)$ & $650(3.8 \%)$ \\
\hline \multicolumn{4}{|l|}{ Surgery $^{1}$} \\
\hline Not cancer-directed & $18483(17.5 \%)$ & $9084(10.3 \%)$ & $9399(55.2 \%)$ \\
\hline Local & $13775(13.1 \%)$ & $13251(15.0 \%)$ & $524(3.1 \%)$ \\
\hline Radical & $71280(67.5 \%)$ & $64493(72.8 \%)$ & $6787(39.9 \%)$ \\
\hline Unknown & $1973(1.9 \%)$ & $1663(1.9 \%)$ & $310(1.8 \%)$ \\
\hline
\end{tabular}




\begin{tabular}{lccc}
\hline & All Patients & Stage I-III & Stage IV \\
\hline Radiation Sequence with Surgery ${ }^{1,2}$ & & & \\
$\quad$ Neoadjuvant & $23020(53.7 \%)$ & $21167(53.5 \%)$ & $1853(55.5 \%)$ \\
$\quad$ Adjuvant & $18578(43.3 \%)$ & $17239(43.6 \%)$ & $1339(40.1 \%)$ \\
$\quad$ Other sequence ${ }^{3}$ & $1291(3.0 \%)$ & $1146(2.9 \%)$ & $145(4.4 \%)$ \\
Chemotherapy $^{4}$ & & & \\
$\quad$ No/unknown & $50377(47.7 \%)$ & $44719(50.5 \%)$ & $5658(33.2 \%)$ \\
Any & $55134(52.3 \%)$ & $43772(49.5 \%)$ & $11362(66.8 \%)$ \\
Year of Diagnosis & & & \\
$\quad$ 1988-2003 & $51171(48.5 \%)$ & $43506(49.2 \%)$ & $7665(45.0 \%)$ \\
$2004-2012$ & $54340(51.5 \%)$ & $44985(50.8 \%)$ & $9355(55.0 \%)$ \\
\hline
\end{tabular}

${ }^{1}$ Initial surgical procedure.

${ }^{2}$ Patients who received both initial radiation and local or radical surgery were included.

${ }^{3}$ Includes radiation both before and after surgery; intraoperative radiation $+/$ - other radiation given before or after surgery; sequence unknown, but both surgery and radiation were performed.

${ }^{4}$ First course.

Lastly, we assessed the influence of ethnicity/race on survival across time (Table 5). African American patients had significantly shorter DSS and OS in all disease stages throughout 1988-2012. In stage I-III rectal cancer, the influence of ethnicity/race on survival varied significantly between 1988-2003 and 2004-2012 with respect to the Hispanic, Native American, and Asian cohorts. The survival differences among Hispanics and Native Americans compared to Whites in 1988-2003 were no longer evident from 2004-2012 (DSS $P_{\text {interaction }}=$ 0.001 , OS $\left.P_{\text {interaction }}=0.058\right)$. Asian patients maintained an OS advantage relative to Whites independent of year of diagnosis, though the improvement in DSS appeared only after 2004. For patients with stage IV disease, the effect of ethnicity/race on outcomes did not differ over time.

\section{DISCUSSION}

Biologic, clinical, and prognostic differences distinguish rectal from colon cancer [19, 20]. Nonetheless, these two diseases are often grouped together in clinical trials and epidemiologic cohorts, and prior investigations specific to RC have been relatively limited in scope. To our knowledge, this is the largest analysis examining the impact of demographic characteristics on the survival of patients with RC. Our study revealed evolving stagespecific effects of sex, age, and ethnicity/race on RC mortality over a twenty-five year period.

Consistent with prior evidence, female sex and younger age emerged as positive prognosticators for cancer-specific and overall survival. A pooled analysis of five clinical trials in locally advanced RC have demonstrated reduced mortality in women and patients younger than 60 years of age [21]. Moreover, our findings in rectal cancer patients are in line with a previous study in colon cancer patients showing that younger women with advanced disease achieve superior outcomes, whereas post-menopausal women have a significantly shorter survival compared to age-matched men [22]. Biologically, derangements in hormonal metabolism are inherent to colorectal carcinogenesis, and sex differences might be partly attributable to the protective effect of estrogen as well as favorable immune responses seen in women after surgical resection [23-25].

Two potential contributing factors we could not account for in our study were duration of therapy and toxicity, both of which have been shown to vary by sex and predict outcomes. Retrospective analyses from CAO/ ARO/AIO-94 show that although women were less likely to receive adequate radiation, they were also more likely to sustain acute toxicity from chemoradiotherapy, and such toxicity was a surrogate for improved OS [26, 27]. Similarly, results from INT-0114 demonstrate increased toxicity to adjuvant chemoradiation and improved survival in women, though toxicity was not independently associated with outcomes in this study [28].

Notably, while sex disparities significantly improved for patients with metastatic disease, they seem to be increasing in patients with early-stage RC. One possible explanation is that women not only have less intrinsically aggressive disease, but may also derive greater treatment intensity with chemoradiation or more benefit from cytotoxic chemotherapy [28]. Mechanistically, a recent translational study implicated $\beta$-tubulin as an androgendriven mechanism of colorectal tumor aggression that is constituitively active in men, and linked to oxaliplatin 
Table 2: Associations between patient characteristics and disease-specific and overall survival

\begin{tabular}{|c|c|c|c|c|c|c|c|c|}
\hline \multirow{3}{*}{ Characteristic } & \multicolumn{4}{|c|}{ Stage I-III } & \multicolumn{4}{|c|}{ Stage IV } \\
\hline & \multicolumn{2}{|c|}{$\begin{array}{c}\text { Disease-Specific } \\
\text { Survival }\end{array}$} & \multicolumn{2}{|c|}{ Overall Survival } & \multicolumn{2}{|c|}{$\begin{array}{c}\text { Disease-Specific } \\
\text { Survival }\end{array}$} & \multicolumn{2}{|c|}{ Overall Survival } \\
\hline & $\begin{array}{l}\text { 5-Year } \\
\text { Rate }\end{array}$ & $\begin{array}{c}\text { HR* } \\
(95 \% \text { CI })\end{array}$ & $\begin{array}{c}\text { 5-Year } \\
\text { Rate }\end{array}$ & $\begin{array}{c}\text { HR* } \\
(95 \% \mathrm{CI})\end{array}$ & $\begin{array}{c}\text { Median, } \\
\text { months }\end{array}$ & $\begin{array}{c}\text { HR* } \\
(95 \% \mathrm{CI})\end{array}$ & $\begin{array}{l}\text { Median, } \\
\text { months }\end{array}$ & $\begin{array}{c}\text { HR* } \\
(95 \% \mathrm{CI})\end{array}$ \\
\hline \multicolumn{9}{|l|}{ Sex } \\
\hline Male & 0.73 & 1 (reference) & 0.59 & 1 (reference) & 16 & 1 (reference) & 14 & 1 (reference) \\
\hline Female & 0.75 & $\begin{array}{c}0.87 \\
(0.84,0.89)\end{array}$ & 0.65 & $\begin{array}{c}0.78 \\
(0.77,0.80)\end{array}$ & 16 & $\begin{array}{c}0.97 \\
(0.94,1.01)\end{array}$ & 14 & $\begin{array}{c}0.96 \\
(0.93,0.99)\end{array}$ \\
\hline$P$ value* & & $<0.001$ & & $<0.001$ & & 0.16 & & 0.019 \\
\hline \multicolumn{9}{|l|}{ Age, years } \\
\hline $18-44$ & 0.80 & $\begin{array}{c}0.44 \\
(0.41,0.47)\end{array}$ & 0.77 & $\begin{array}{c}0.27 \\
(0.26,0.29)\end{array}$ & 17 & $\begin{array}{c}0.74 \\
(0.69,0.80)\end{array}$ & 16 & $\begin{array}{c}0.67 \\
(0.63,0.72)\end{array}$ \\
\hline $45-54$ & 0.81 & $\begin{array}{c}0.44 \\
(0.42,0.46)\end{array}$ & 0.77 & $\begin{array}{c}0.28 \\
(0.27,0.29)\end{array}$ & 18 & $\begin{array}{c}0.70 \\
(0.66,0.74)\end{array}$ & 17 & $\begin{array}{c}0.64 \\
(0.60,0.67)\end{array}$ \\
\hline $55-64$ & 0.79 & $\begin{array}{c}0.50 \\
(0.48,0.52)\end{array}$ & 0.72 & $\begin{array}{c}0.36 \\
(0.35,0.37)\end{array}$ & 17 & $\begin{array}{c}0.77 \\
(0.73,0.81)\end{array}$ & 15 & $\begin{array}{c}0.73 \\
(0.69,0.77)\end{array}$ \\
\hline $65-74$ & 0.75 & $\begin{array}{c}0.61 \\
(0.59,0.63)\end{array}$ & 0.62 & $\begin{array}{c}0.53 \\
(0.52,0.54)\end{array}$ & 15 & $\begin{array}{c}0.87 \\
(0.83,0.92)\end{array}$ & 13 & $\begin{array}{c}0.85 \\
(0.81,0.89)\end{array}$ \\
\hline 75 and older & 0.64 & 1 (reference) & 0.43 & 1 (reference) & 14 & 1 (reference) & 11 & 1 (reference) \\
\hline$P$ value* & & $<0.001$ & & $<0.001$ & & $<0.001$ & & $<0.001$ \\
\hline \multicolumn{9}{|l|}{ Ethnicity/Race } \\
\hline White & 0.75 & 1 (reference) & 0.62 & 1 (reference) & 16 & 1 (reference) & 14 & 1 (reference) \\
\hline $\begin{array}{l}\text { African } \\
\text { American }\end{array}$ & 0.69 & $\begin{array}{c}1.30 \\
(1.24,1.37)\end{array}$ & 0.56 & $\begin{array}{c}1.23 \\
(1.18,1.27)\end{array}$ & 15 & $\begin{array}{c}1.14 \\
(1.08,1.22)\end{array}$ & 13 & $\begin{array}{c}1.15 \\
(1.09,1.22)\end{array}$ \\
\hline Asian & 0.75 & $\begin{array}{c}0.93 \\
(0.88,0.99)\end{array}$ & 0.65 & $\begin{array}{c}0.88 \\
(0.84,0.92)\end{array}$ & 16 & $\begin{array}{c}0.95 \\
(0.88,1.03)\end{array}$ & 14 & $\begin{array}{c}0.98 \\
(0.91,1.05)\end{array}$ \\
\hline Hispanic & 0.72 & $\begin{array}{c}1.10 \\
(1.05,1.16)\end{array}$ & 0.61 & $\begin{array}{c}1.02 \\
(0.98,1.06)\end{array}$ & 17 & $\begin{array}{c}0.97 \\
(0.91,1.04)\end{array}$ & 14 & $\begin{array}{c}0.99 \\
(0.93,1.05)\end{array}$ \\
\hline $\begin{array}{l}\text { Native } \\
\text { American }\end{array}$ & 0.69 & $\begin{array}{c}1.10 \\
(0.89,1.36)\end{array}$ & 0.55 & $\begin{array}{c}1.18 \\
(1.00,1.38)\end{array}$ & 17 & $\begin{array}{c}0.88 \\
(0.70,1.11)\end{array}$ & 15 & $\begin{array}{c}0.86 \\
(0.70,1.07)\end{array}$ \\
\hline$P$ value* & & $<0.001$ & & $<0.001$ & & $<0.001$ & & $<0.001$ \\
\hline
\end{tabular}

* Based on the multivariable Cox proportional hazards regression model adjusting for the variables included in the table and histology, differentiation, T stage, N stage, AJCC TNM7 stage (for stage I-III), surgery, radiation therapy, sequence of radiation to surgery, chemotherapy, number of lymph nodes resected, CEA level, year of diagnosis, marital status at diagnosis, and stratified by SEER registration sites.

and irinotecan resistance as well as poor outcomes [29]. Other pharmacogenomic data support the notion that sex modulates the sensitivity to chemotherapy [30].

The narrowing of sex outcome disparities in metastatic RC after 2004 likely reflects multiple interacting factors and the expansion of available chemotherapeutics. While we could not describe the specific chemotherapy prescribed, recent data encompassing private, academic, and community-based practice patterns from 2004 to 2011 demonstrate that men and women are equally likely 
Table 3: Associations between sex and disease-specific and overall survival by age at diagnosis

\begin{tabular}{|c|c|c|c|c|c|}
\hline \multirow{2}{*}{ Stage } & \multirow{2}{*}{ Age Group } & \multicolumn{2}{|c|}{ Disease-Specific Survival } & \multicolumn{2}{|c|}{ Overall Survival } \\
\hline & & HR* $(95 \%$ CI $)$ & $P$ value $\dagger$ & HR* $(95 \% \mathrm{CI})$ & $P$ value \\
\hline \multirow[t]{6}{*}{ I-III } & 18-44 years & $0.86(0.77,0.97)$ & 0.014 & $0.80(0.72,0.89)$ & $<0.001$ \\
\hline & $45-54$ years & $0.83(0.76,0.89)$ & $<0.001$ & $0.80(0.74,0.86)$ & $<0.001$ \\
\hline & $55-64$ years & $0.83(0.78,0.88)$ & $<0.001$ & $0.78(0.74,0.82)$ & $<0.001$ \\
\hline & $65-74$ years & $0.88(0.83,0.93)$ & $<0.001$ & $0.78(0.74,0.81)$ & $<0.001$ \\
\hline & 75 and older & $0.89(0.85,0.93)$ & $<0.001$ & $0.78(0.76,0.81)$ & $<0.001$ \\
\hline & $P_{\text {for interaction }} \dagger$ & 0.27 & & 0.94 & \\
\hline \multirow[t]{6}{*}{ IV } & $18-44$ years & $0.79(0.70,0.89)$ & $<0.001$ & $0.78(0.69,0.88)$ & $<0.001$ \\
\hline & $45-54$ years & $1.01(0.92,1.11)$ & 0.83 & $1.02(0.94,1.11)$ & 0.67 \\
\hline & 55-64 years & $0.97(0.90,1.05)$ & 0.45 & $0.96(0.90,1.03)$ & 0.29 \\
\hline & $65-74$ years & $0.99(0.92,1.07)$ & 0.87 & $0.95(0.89,1.02)$ & 0.15 \\
\hline & 75 and older & $1.01(0.94,1.08)$ & 0.87 & $0.99(0.93,1.06)$ & 0.86 \\
\hline & $P_{\text {for interaction }} \dagger$ & 0.013 & & 0.005 & \\
\hline
\end{tabular}

* Males as a reference.

$\uparrow$ Based on Wald test in the multivariable Cox proportional hazards regression model adjusting for ethnicity/race, histology, differentiation, T stage, N stage, AJCC TNM7 stage (for stage I-III), surgery, radiation therapy, sequence of radiation to surgery, chemotherapy, number of lymph nodes resected, CEA level, year of diagnosis, marital status at diagnosis, and stratified by SEER registration sites.

Table 4: Associations between sex and disease-specific and overall survival by year of diagnosis

\begin{tabular}{|c|c|c|c|c|c|}
\hline \multirow{2}{*}{ Stage } & \multirow{2}{*}{ Year of Diagnosis } & \multicolumn{2}{|c|}{ Disease-Specific Survival } & \multicolumn{2}{|c|}{ Overall Survival } \\
\hline & & HR* $(95 \% \mathrm{CI})$ & $P$ value $\dagger$ & HR* $(95 \% \mathrm{CI})$ & $P$ value $\dagger$ \\
\hline \multirow[t]{3}{*}{ I-III } & $1988-2003$ & $0.86(0.83,0.89)$ & $<0.001$ & $0.77(0.75,0.79)$ & $<0.001$ \\
\hline & 2004-2012 & $0.88(0.84,0.92)$ & $<0.001$ & $0.81(0.78,0.84)$ & $<0.001$ \\
\hline & $P_{\text {for interaction }} \dagger$ & 0.46 & & 0.040 & \\
\hline \multirow[t]{3}{*}{ IV } & $1988-2003$ & $0.93(0.88,0.98)$ & 0.005 & $0.93(0.88,0.97)$ & 0.002 \\
\hline & 2004-2012 & $1.02(0.97,1.08)$ & 0.40 & $0.99(0.95,1.04)$ & 0.75 \\
\hline & $P_{\text {for interaction }} \dagger$ & 0.009 & & 0.050 & \\
\hline
\end{tabular}

* Males as a reference.

$\dagger$ Based on Wald test in the multivariable Cox proportional hazards regression model adjusting for age, ethnicity/race, histology, differentiation, T stage, N stage, AJCC TNM7 stage (for stage I-III), surgery, radiation therapy, sequence of radiation to surgery, chemotherapy, number of lymph nodes resected, CEA level, marital status at diagnosis, and stratified by SEER registration sites.

to receive cetuximab or bevacizumab in the first-line metastatic setting [31].

With regards to ethnicity/race, African Americans had a significantly shorter survival in all stages of disease, which is consistent with several other studies documenting ethnic/racial disparities in cancer-associated outcomes [32-34]. African Americans have previously been reported to receive less adjuvant chemotherapy and curative treatment modalities [32, 33]. However, data from the BRiTE registry and N9741 suggest equivalent survival between African Americans and Whites, though also showed ethnic/racial differences in pharmacogenetic profiles [35, 36]. After accounting for important confounding variables, including receipt of chemotherapy, radiation, and surgery (including number of lymph nodes resected), our data demonstrated that the black-white 
disparities have persisted over time. These findings imply that, among other reasons, response to therapy may vary by ethnicity/race. This hypothesis is supported by previous data showing significantly lower response rates to bevacizumab-based therapy in African Americans as compared to Whites [35, 36].

In addition to African Americans, from 1988 to 2003, Hispanics and American Natives with stage I-III RC had a poorer DSS and OS compared to Whites. After 2004, the prognosis for Hispanics, Native Americans, and Asians markedly improved compared to Whites, with the greatest benefit most evident among Native Americans. This may reflect improved access to care in underserved populations.

In summary, we observe that sex disparities in outcome have narrowed in patients with metastatic RC, but persist in patients with stage I-III disease. These differences are most evident among young patients aged 18-44 years old, where sex disparities have even widened in stage I-III rectal cancer. Furthermore, younger age and female sex are associated with favorable outcome in all disease stages. In stage IV disease, the sex disparity favoring women was limited to the age 18-44 yr cohort. Hispanics and Native Americans were diagnosed at a younger age than Whites, with the greatest difference seen between Native American and white women. Among Whites, African Americans and Asians, women were diagnosed at an older age than men. These findings may have implications for future prevention strategies. While outcomes have significantly improved for Asians, Hispanics, and Native Americans with stage I-III rectal cancer, mortality in African American patients improved modestly overall and remained significantly higher than other ethnicities/races across all stages. For patients with stage IV rectal cancer, the effect of ethnicity/race on outcome did not change over time.

The main limitations of our study are the missing information regarding the type and duration of chemotherapy and radiation administered, surgical approach, presence of comorbidities and socioeconomic

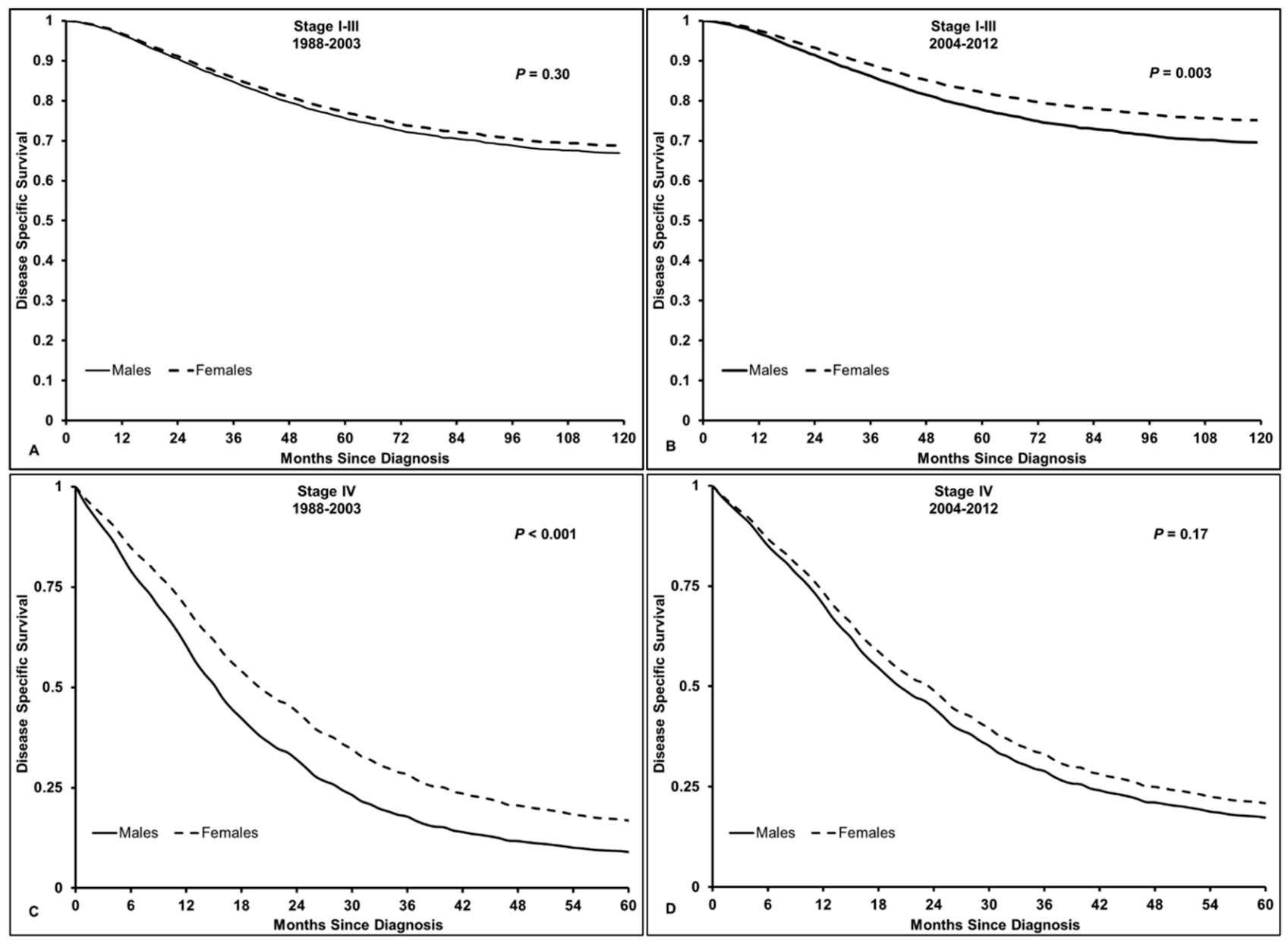

Figure 1: Disease-specific survival in patients with rectal cancer, aged 18-44 years old. A. Stage I-III RC from 1988-2003, HR 0.92 (95\% CI 0.79, 1.08, $P=0.30)$; B. Stage I-III RC from 2004-2012, HR 0.75 (95\% CI 0.62, 0.90, $P=0.003)$; C. Stage IV RC from 1988-2003, HR 0.64 (95\% CI 0.53, 0.78, $P<0.001)$; D. Stage IV RC from 2004-2012, HR $0.88(95 \%$ CI $0.74,1.06, P=0.17) . P$ interaction stage I-III RC $=0.090, P_{\text {interaction }}$ stage IV RC $=0.018$. Males used as a reference. 
Table 5: Associations between ethnicity/race and disease-specific and overall survival by year of diagnosis

\begin{tabular}{|c|c|c|c|c|c|}
\hline & \multirow{2}{*}{ Race } & \multicolumn{2}{|c|}{ Disease-Specific Survival } & \multicolumn{2}{|c|}{ Overall Survival } \\
\hline & & $H R *(95 \% C I)$ & $P$ value $\dagger$ & $H R *(95 \% \mathrm{CI})$ & $P$ value $\uparrow$ \\
\hline \multicolumn{6}{|l|}{ Stage I-III } \\
\hline \multirow[t]{4}{*}{$1988-2003$} & African American & $1.38(1.29,1.46)$ & $<0.001$ & $1.25(1.19,1.31)$ & $<0.001$ \\
\hline & Asian & $0.96(0.90,1.04)$ & 0.32 & $0.89(0.84,0.94)$ & $<0.001$ \\
\hline & Hispanic & $1.13(1.06,1.21)$ & $<0.001$ & $1.05(1.00,1.11)$ & 0.056 \\
\hline & Native American & $1.35(1.05,1.74)$ & 0.020 & $1.30(1.07,1.59)$ & 0.010 \\
\hline \multirow[t]{5}{*}{ 2004-2012 } & African American & $1.20(1.11,1.29)$ & $<0.001$ & $1.18(1.12,1.26)$ & $<0.001$ \\
\hline & Asian & $0.87(0.79,0.95)$ & 0.002 & $0.84(0.78,0.90)$ & $<0.001$ \\
\hline & Hispanic & $1.05(0.97,1.13)$ & 0.21 & $0.97(0.91,1.03)$ & 0.34 \\
\hline & Native American & $0.85(0.63,1.14)$ & 0.27 & $1.04(0.83,1.29)$ & 0.76 \\
\hline & $P_{\text {for interaction }}{ }^{\dagger}$ & 0.001 & & 0.058 & \\
\hline \multicolumn{6}{|l|}{ Stage IV } \\
\hline \multirow[t]{4}{*}{$1988-2003$} & African American & $1.18(1.08,1.29)$ & $<0.001$ & $1.18(1.09,1.28)$ & $<0.001$ \\
\hline & Asian & $0.99(0.89,1.09)$ & 0.79 & $1.01(0.92,1.12)$ & 0.79 \\
\hline & Hispanic & $1.00(0.91,1.10)$ & 0.97 & $1.04(0.95,1.13)$ & 0.40 \\
\hline & Native American & $0.90(0.66,1.22)$ & 0.49 & $0.86(0.64,1.15)$ & 0.31 \\
\hline \multirow[t]{5}{*}{ 2004-2012 } & African American & $1.10(1.01,1.20)$ & 0.023 & $1.12(1.04,1.21)$ & 0.004 \\
\hline & Asian & $0.92(0.83,1.02)$ & 0.095 & $0.94(0.85,1.03)$ & 0.17 \\
\hline & Hispanic & $0.94(0.86,1.02)$ & 0.14 & $0.94(0.87,1.02)$ & 0.15 \\
\hline & Native American & $0.88(0.65,1.18)$ & 0.39 & $0.88(0.66,1.16)$ & 0.35 \\
\hline & $P_{\text {for interaction }}{ }^{\dagger}$ & 0.61 & & 0.38 & \\
\hline
\end{tabular}

* Whites as a reference.

$\dagger$ Based on Wald test in the multivariable Cox proportional hazards regression model adjusting for sex, age, histology, differentiation, T stage, N stage, AJCC TNM7 stage (for stage I-III), surgery, radiation therapy, sequence of radiation to surgery, chemotherapy, number of lymph nodes resected, CEA level, marital status at diagnosis, and stratified by SEER registration sites.

status, as these data are not available in the SEER registry. This renders it impossible to draw conclusions regarding the differential benefit of chemotherapeutics and biologicals in different populations. By focusing on outcome disparities before and after 2004, we were not able to systematically account for the differential effects of therapies approved at other time points. In addition, we did not have access to information on comorbidities, but by assessing DSS, we tried to limit its influence on outcomes. Nonetheless, our study represents the largest cohort of RC patients, reflects mortality data after the implementation of recent, important changes in care standards, and accounts for overall treatment rendered.

Future trials should address whether response to biologics and cytotoxic chemotherapy may vary by ethnicity/race and sex, in order to better personalize the management of patients with rectal cancer.
Additionally, the implementation of prospective population-based registries containing clinicopathologic, pharmacogenetic, and socioeconomic data will be instrumental to achieving these objectives.

\section{MATERIALS AND METHODS}

\section{Study design}

The SEER database 1973-2012 (Version April 2015) was used for this analysis [18]. The SEER Program, sponsored by the National Cancer Institute (NCI), provides information on the demographics, primary tumor site, tumor morphology, and stage at diagnosis, first course of treatment including surgery and radiation, and survival of all newly diagnosed cancer patients by registration site. Information on the first course of chemotherapy 
was obtained from NCI/SEER Program through a special request for customized data. The SEER registries expanded from 9 sites in 1973 to 18 in 2000, covering about $28 \%$ of the US population and oversampling Hispanics (38\%), Native Americans (44\%), Asians (50\%), and Pacific Islanders (67\%).

\section{Patient population}

Patients diagnosed with rectal cancer (according to the International Classification of Diseases for Oncology, 3rd Edition [ICD-O-3] site code C20.9 and histologic type ICD-O-3 codes 8000-8152, 8154-8231, 8243$8245,8250-8576,8940-8950,8980-8981)$ between 1988 and 2012 were identified from the SEER database $(\mathrm{n}=$ 135,243). Those diagnosed before $1988(\mathrm{n}=33,622)$ were excluded due to limited staging information such as primary tumor extension, lymph node involvement, and/ or distant metastasis. Other exclusion criteria included SEER historic stage A (in situ or un-staged disease), age ( $<18$ or unknown), type of reporting source (autopsy only or death certificate), lack of diagnostic confirmation (not microscopically confirmed), no or unknown follow-up, and unknown ethnicity/race. The AJCC staging $7^{\text {th }}$ edition was used to define stage I, II, III, and IV based on primary tumor extension, lymph node involvement, and/or distant metastasis. Patients with AJCC stage 0 disease were excluded. A total of 105,511 patients met the eligibility criteria and were included in the final analysis. The patient population was further grouped into five ethnic/ racial cohorts as follows: non-Hispanic Whites, nonHispanic African Americans, non-Hispanic Asian/Pacific Islanders, Hispanics, and Native Americans. Hispanics were identified by using the North American Association of Central Cancer Registries (NAACCR) Hispanic Identification Algorithm (NHIA). Throughout the text, the term White refers to non-Hispanic Whites unless stated otherwise. Similarly, the terms African American, Asian and Native American exclude Hispanics.

Rectum (C20.9)-specific surgery codes 20 (19831997) and 20-28 (1998-2012) were summarized as local surgical procedures, whereas codes 30-70 (1983-1997) and 30-90 (1998-2012) were defined as radical surgery. Codes 00-10 (1983-1997) and 00, 10-14 (1998-2012) were considered as non-surgical procedures.

\section{Statistical analysis}

The main outcomes of the study were rectal cancer or disease-specific survival (DSS) calculated from date of diagnosis to the date of death from rectal cancer and overall survival (OS), defined as the interval from date of diagnosis to the date of death. OS and DSS were censored at date of last contact, December 31, 2012, 10 years after diagnosis, or date of death from other causes for DSS, whichever came first. For subjects who were censored for OS $(\mathrm{n}=52,587)$, the median follow-up time was 71 months (interquartile ranges: $30-120$ months). A multivariable Cox proportional hazards regression model was used to evaluate the association between sex, age, and ethnicity/race and OS and DSS when adjusting for other potential prognostic factors available in the SEER database. We considered marital status at diagnosis, histology, tumor differentiation, tumor stage, lymph node stage, AJCC stage, the number of lymph nodes examined, surgical procedure, use of radiation therapy, sequence of surgery and radiation therapy, chemotherapy, CEA level (year of diagnosis 2004 or later), SEER registry site, and year of diagnosis as covariates in the Cox regression model. A likelihood ratio test was performed to test the interactions between sex, age, ethnicity/race, and stage on DSS and OS. We evaluated graphically departures from the proportional hazards assumption for the model using smoothed plots of weighted Schoenfeld residuals. No violation was detected. To evaluate age at diagnosis by sex and ethnicity/race, $P$ values were calculated based on Wilcoxon two-sample test to compare sex differences within each ethnicity/race, whereas the Kruskal-Wallis test was used to compare ethnic/racial differences for males and females separately. Analyses for localized (AJCC stage I, II, or III) and metastatic disease (AJCC stage IV) were conducted separately using SAS Version 9.4 (SAS Institute, Cary, NC) at a significance level of 0.05. All tests were 2-sided.

\section{ACKNOWLEDGMENTS}

We would like to thank Mandi $\mathrm{Yu}, \mathrm{PhD}$ from the Division of Cancer Control and Population Sciences at the National Cancer Institute (NCI) for critical review of the manuscript.

\section{CONFLICTS OF INTEREST} disclose.

All authors have no potential conflicts of interest to

\section{GRANT SUPPORT}

Martin D. Berger received a grant from the Swiss Cancer League (BIL KLS-3334-02-2014) and the Werner and Hedy Berger-Janser Foundation for cancer research.

This work was supported by the National Institute of Health P30CA014089, the Gloria Borges Wunderglo Project, and the Dhont Family Foundation.

The content is solely the responsibility of the authors and does not necessarily represent the official views of the National Cancer Institute or the National Institutes of Health. 


\section{REFERENCES}

1. Siegel RL, Miller KD, Jemal A. Cancer statistics, 2015. CA Cancer J Clin 65:5-29, 2015.

2. Rutter CM, Johnson EA, Feuer EJ, Knudsen AB, Kuntz $\mathrm{KM}$, Schrag D. Secular trends in colon and rectal cancer relative survival. J Natl Cancer Inst 105:1806-13, 2013.

3. Meyer JE, Narang T, Schnoll-Sussman FH, Pochapin MB, Christos PJ, Sherr DL. Increasing incidence of rectal cancer in patients aged younger than 40 years: an analysis of the surveillance, epidemiology, and end results database. Cancer 116:4354-9, 2010.

4. Bailey CE, Hu CY, You YN, Bednarski BK, RodriguezBigas MA, Skibber JM, Cantor SB, Chang GJ. Increasing disparities in the age-related incidences of colon and rectal cancers in the United States, 1975-2010. JAMA Surg 150:17-22, 2015.

5. Ahnen DJ, Wade SW, Jones WF, Sifri R, Mendoza Silveiras J, Greenamyer J, Guiffre S, Axilbund J, Spiegel A, You YN. The increasing incidence of young-onset colorectal cancer: a call to action. Mayo Clin Proc 89:216-24, 2014.

6. You YN, Xing Y, Feig BW, Chang GJ, Cormier JN. Youngonset colorectal cancer: is it time to pay attention? Arch Intern Med 172:287-9, 2012.

7. Wallace K, Sterba KR, Gore E, Lewin DN, Ford ME, Thomas MB, Alberg AJ. Prognostic factors in relation to racial disparity in advanced colorectal cancer survival. Clin Colorectal Cancer 12:287-93, 2013.

8. Wallace K, Hill EG, Lewin DN, Williamson G, Oppenheimer S, Ford ME, Wargovich MJ, Berger FG, Bolick SW, Thomas MB, Alberg AJ. Racial disparities in advanced-stage colorectal cancer survival. Cancer Causes Control 24:463-71, 2013.

9. Sauer R, Becker H, Hohenberger W, Rödel C, Wittekind C, Fietkau R, Martus P, Tschmelitsch J, Hager E, Hess CF, Karstens JH, Liersch T, Schmidberger H et al. Preoperative versus postoperative chemoradiotherapy for rectal cancer. N Engl J Med 351:1731-40, 2004.

10. Andre $\mathrm{T}$, Boni C, Mounedji-Boudiaf L, Navarro M, Tabernero J, Hickish T, Topham C, Zaninelli M, Clingan P, Bridgewater J, Tabah-Fisch I, de Gramont A. Oxaliplatin, fluorouracil, and leucovorin as adjuvant treatment for colon cancer. N Engl J Med 350:2343-51, 2004

11. Goldberg RM, Sargent DJ, Morton RF, Fuchs CS, Ramanathan RK, Williamson SK, Findlay BP, Pitot HC, Alberts SR. A randomized controlled trial of fluorouracil plus leucovorin, irinotecan, and oxaliplatin combinations in patients with previously untreated metastatic colorectal cancer. J Clin Oncol 22:23-30, 2004.

12. Hurwitz H, Fehrenbacher L, Novotny W, Cartwright T, Hainsworth J, Heim W, Berlin J, Baron A, Griffing S, Holmgren E, Ferrara N, Fyfe G, Rogers B et al. Bevacizumab plus irinotecan, fluorouracil, and leucovorin for metastatic colorectal cancer. N Engl J Med 350:233542, 2004.
13. Cunningham D, Humblet Y, Siena S, Khayat D, Bleiberg H, Santoro A, Bets D, Mueser M, Harstrick A, Verslype C, Chau I, Van Cutsem E. Cetuximab monotherapy and cetuximab plus irinotecan in irinotecan-refractory metastatic colorectal cancer. N Engl J Med 351:337-45, 2004.

14. Zeng C, Wen W, Morgans AK, Pao W, Shu XO, Zheng W. Disparities by Race, Age, and Sex in the Improvement of Survival for Major Cancers: Results From the National Cancer Institute Surveillance, Epidemiology, and End Results (SEER) Program in the United States, 1990 to 2010. JAMA Oncol 1:88-96, 2015.

15. Robbins AS, Siegel RL, Jemal A. Racial disparities in stagespecific colorectal cancer mortality rates from 1985 to 2008 . J Clin Oncol 30:401-5, 2012.

16. Siegel RL, Jemal A, Ward EM. Increase in incidence of colorectal cancer among young men and women in the United States. Cancer Epidemiol Biomarkers Prev 18:16958, 2009.

17. Paulson EC, Wirtalla C, Armstrong K, Mahmoud NN. Gender influences treatment and survival in colorectal cancer surgery. Dis Colon Rectum 52:1982-91, 2009.

18. SEER Research Data 1973-2012. Surveillance E, and End Results (SEER) Program (www.seer.cancer.gov) Research Data (1973-2012), National Cancer Institute, DCCPS, Surveillance Research Program, Surveillance Systems Branch, released April 2015, based on the November 2014 submission.

19. Frattini M, Balestra D, Suardi S, Oggionni M, Alberici P, Radice P, Costa A, Daidone MG, Leo E, Pilotti S, Bertario L, Pierotti MA. Different genetic features associated with colon and rectal carcinogenesis. Clin Cancer Res 10:401521, 2004 .

20. Lee YC, Lee YL, Chuang JP, Lee JC. Differences in survival between colon and rectal cancer from SEER data. PLoS One 8:e78709, 2013.

21. Valentini V, van Stiphout RG, Lammering G, Gambacorta MA, Barba MC, Bebenek M, Bonnetain F, Bosset JF, Bujko K, Cionini L, Gerard JP, Rödel C, Sainato A et al. Nomograms for predicting local recurrence, distant metastases, and overall survival for patients with locally advanced rectal cancer on the basis of European randomized clinical trials. J Clin Oncol 29:3163-72, 2011.

22. Hendifar A, Yang D, Lenz F, Lurje G, Pohl A, Lenz C, Ning Y, Zhang W, Lenz HJ. Gender disparities in metastatic colorectal cancer survival. Clin Cancer Res 15:6391-7, 2009.

23. Barzi A, Lenz AM, Labonte MJ, Lenz HJ. Molecular pathways: Estrogen pathway in colorectal cancer. Clin Cancer Res 19:5842-8, 2013.

24. Kennelly R, Kavanagh DO, Hogan AM, Winter DC. Oestrogen and the colon: potential mechanisms for cancer prevention. Lancet Oncol 9:385-91, 2008.

25. Bird MD, Karavitis J, Kovacs EJ. Sex differences and estrogen modulation of the cellular immune response after injury. Cell Immunol 252:57-67, 2008. 
26. Wolff HA, Conradi LC, Beissbarth T, Leha A, Hohenberger W, Merkel S, Fietkau R, Raab HR, Tschmelitsch J, Hess CF, Becker H, Wittekind C, Sauer R et al. Gender affects acute organ toxicity during radiochemotherapy for rectal cancer: long-term results of the German $\mathrm{CAO} / \mathrm{ARO} / \mathrm{AIO}-94$ phase III trial. Radiother Oncol 108:48-54, 2013.

27. Fietkau R, Rödel C, Hohenberger W, Raab R, Hess C, Liersch T, Becker H, Wittekind C, Hutter M, Hager E, Karstens J, Ewald H, Christen $\mathrm{N}$ et al. Rectal cancer delivery of radiotherapy in adequate time and with adequate dose is influenced by treatment center, treatment schedule, and gender and is prognostic parameter for local control: results of study CAO/ARO/AIO-94. Int J Radiat Oncol Biol Phys 67:1008-19, 2007.

28. Tepper JE, O'Connell M, Niedzwiecki D, Hollis DR, Benson AB 3rd, Cummings B, Gunderson LL, Macdonald JS, Martenson JA, Mayer RJ. Adjuvant therapy in rectal cancer: analysis of stage, sex, and local control-final report of intergroup 0114. J Clin Oncol 20:1744-50, 2002.

29. Mariani M, Zannoni GF, Sioletic S, Sieber S, Martino C, Martinelli E, Coco C, Scambia G, Shahabi S, Ferlini C. Gender influences the class III and V beta-tubulin ability to predict poor outcome in colorectal cancer. Clin Cancer Res 18:2964-75, 2012.

30. Ning Y, Gerger A, Zhang W, Hanna DL, Yang D, Winder T, Wakatsuki T, Labonte MJ, Stintzing S, Volz N, Sunakawa Y, Stremitzer S, El-Khoueiry R et al. Plastin polymorphisms predict gender- and stage-specific colon cancer recurrence after adjuvant chemotherapy. Mol Cancer Ther 13:528-39, 2014.

31. Abrams TA, Meyer G, Schrag D, Meyerhardt JA, Moloney J, Fuchs CS. Chemotherapy usage patterns in a US-wide cohort of patients with metastatic colorectal cancer. J Natl Cancer Inst 106:djt371, 2014.

32. Morris AM, Billingsley KG, Hayanga AJ, Matthews B, Baldwin LM, Birkmeyer JD. Residual treatment disparities after oncology referral for rectal cancer. J Natl Cancer Inst 100:738-44, 2008.

33. Morris AM, Wei Y, Birkmeyer NJ, Birkmeyer JD. Racial disparities in late survival after rectal cancer surgery. J Am Coll Surg 203:787-94, 2006.

34. Murphy CC, Harlan LC, Warren JL, Geiger AM. Race and Insurance Differences in the Receipt of Adjuvant Chemotherapy Among Patients With Stage III Colon Cancer. J Clin Oncol 33:2530-6, 2015.

35. Polite BN, Sing A, Sargent DJ, Grothey A, Berlin J, Kozloff $\mathrm{M}$, Feng S. Exploring racial differences in outcome and treatment for metastatic colorectal cancer: results from a large prospective observational cohort study (BRiTE). Cancer 118:1083-90, 2012.

36. Sanoff HK, Sargent DJ, Green EM, McLeod HL, Goldberg RM. Racial differences in advanced colorectal cancer outcomes and pharmacogenetics: a subgroup analysis of a large randomized clinical trial. J Clin Oncol 27:4109-15, 2009. 